\title{
GRAIN REFINEMENT IN HYPEREUTECTOID STEEL BY SEMI-SOLID PROCESSING FOLLOWED BY MECHANICAL WORKING
}

\author{
${ }^{1}$ Kateřina RUBEŠOVÁ, ${ }^{1}$ Michal PEKOVIĆ, ${ }^{1}$ Hana JIRKOVÁ, ${ }^{2}$ David HRADIL \\ ${ }^{1}$ University of West Bohemia, Regional Technology Institute, Faculty of Mechanical Engineering, Pilsen, \\ Czech Republic, EU, krubesov@rti.zcu.cz \\ ${ }^{2}$ COMTES FHT a.s., Průmyslová 995, Dobřany, 334 41, Czech Republic, EU, david.hradil@comtesfht.cz
}

https://doi.org/10.37904/metal.2020.3473

\begin{abstract}
Research into new forming methods has yielded new techniques of altering the microstructure in hypereutectoid steels. An innovative approach to processing can lead to improved mechanical properties thanks to elimination of problematic and undesirable sharp-edged carbides which are very difficult to dissolve. This paper explores an unconventional method of refining the grain in and removing primary sharp-edged chromium carbides from X210Cr12 hypereutectoid tool steel.

The process route applied to input stock comprised semi-solid processing followed by forming below the solidus temperature. The goal of the study was to determine the impact of the applied strain on microstructural evolution and grain refinement. In these experiments, the material was heated to above the solidus temperature and then either cooled without any other intervention or cooled to a forming temperature and then formed using five to ten deformation steps. Higher number of deformation steps led to much finer microstructure and higher hardness which increased from the initial $673 \mathrm{HV} 10$ to $873 \mathrm{HV} 10$. This procedure produced a very fine microstructure with grains of approximately $1 \mu \mathrm{m}$ and a fine dispersion of chromium carbides. Since the resulting material was very hard and brittle, it had to be tempered. Tempering was performed once at $300^{\circ} \mathrm{C}$ for 1 hour or twice at $530^{\circ} \mathrm{C}$, for 1 hour in each operation.
\end{abstract}

Keywords: Metallurgy, steel, properties, applications, testing methods

\section{INTRODUCTION}

New processing methods for conventional materials continue to be sought to enable these materials to be deployed in various applications, including special ones. One of such methods is unconventional semi-solid processing of hypereutectoid tool steels. Semi-solid processing involves partial melting of the workpiece $[1,2]$. At high temperatures, primary chromium carbides are removed and the subsequent forming can produce microstructures with grains of approximately $1 \mu \mathrm{m}$ and very fine precipitates. In addition, the entire heat treatment becomes shorter than the conventional routes. Conventional processing of these steels comprises quenching and subsequent tempering, typically multiple tempering. When semi-solid processing is used, the final tempering operations can be omitted or shortened substantially.

Sharp-edged primary chromium carbides greatly improve resistance to wear and creep. However, due to their large size, they also impair toughness. They are usually present in high-chromium tool steels. Most carbides in tool steels produced by the conventional metallurgical route are the primary $\mathrm{M}_{7} \mathrm{C}_{3}$ type carbides which are very difficult to eliminate by conventional processing. Sometimes these steels must be produced using powder metallurgy [3-5]. These reasons have led to developing a process route which combines semi-solid processing and subsequent forming, removes sharp-edged chromium carbides and produces very fine chromium carbides which are uniformly distributed in a martensitic matrix [6-8]. 
The resulting material exhibits high hardness along with brittleness which is undesirable for practical use. Therefore, an important step is subsequent tempering. The right tempering route leads to a slight decrease in hardness but improves toughness.

\section{MATERIALS AND METHODS}

The experimental material was $\mathrm{X} 210 \mathrm{Cr} 12$ tool steel. It is a typical representative of hypereutectoid steels with sharp-edged chromium carbides. It was developed for cold working and its primary use is in punching and press-forming tools, typically in intricate progressive and combined punching tools. Given its chemical composition and a wide freezing range, it is suitable for semi-solid processing (Table 1) [4]. It was supplied in an annealed condition. The as-received microstructure contained large sharp-edged chromium carbides and very fine cementite particles in a ferritic matrix (Figure 1). Experimental specimens had a $30 \mathrm{~mm}$ diameter and $55 \mathrm{~mm}$ length. To ensure that the partially melted workpiece can be handled safely, the feedstock was placed in a container of SJ355 low-carbon steel which had a higher melting temperature [6-7].

Table 1 Chemical composition of the steel under investigation (wt. \%)

\begin{tabular}{|c|c|c|c|c|c|c|}
\hline $\mathbf{C}$ & $\mathbf{C r}$ & $\mathbf{M n}$ & $\mathbf{S i}$ & $\mathbf{N i}$ & $\mathbf{P}$ & $\mathbf{S}$ \\
\hline 1.8 & 12 & 0.3 & 0.35 & $\max 0.5$ & $\max 0.03$ & $\max 0.035$ \\
\hline
\end{tabular}

The heating temperature and time were $1240^{\circ} \mathrm{C}$ and 30 minutes, respectively [5,6]. At this temperature, approximately $15 \%$ liquid phase is present in the material. After holding at temperature, the workpiece was cooled rapidly in water for 2 seconds and then placed in a furnace at $1080^{\circ} \mathrm{C}$ for 1.5 minutes. According to $\mathrm{X} 210 \mathrm{Cr} 12$ tool steel's data sheet, $1080^{\circ} \mathrm{C}$ is the recommended forging temperature. Workpieces removed from the furnace were either quenched in water to room temperature or mechanically worked using five or ten deformation steps (Table 2). The amount of reduction was the same for all the steps: $30 \mathrm{~mm}$. In the series of 10 deformation steps, reheating to $1080^{\circ} \mathrm{C}$ for 10 minutes was carried out after the first five steps. The purpose of the introduced strain was to break up and redistribute the ledeburite network which had formed upon semi-solid processing and to initiate dynamic recrystallization in austenite [9-10].

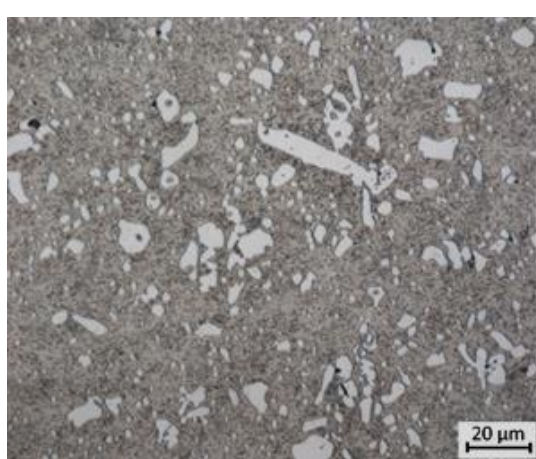

Figure 1 - As-received condition of X210Cr12 steel, light micrograph

Table 2 Parameters for routes involving semi-solid processing

\begin{tabular}{|c|c|c|c|c|c|}
\hline $\begin{array}{c}\text { T heating }\left({ }^{\circ} \mathbf{C}\right) \\
\text { /time }(\mathbf{m i n})\end{array}$ & $\begin{array}{c}\text { Quenching } \\
\mathbf{m} \text { edium/t (s) }\end{array}$ & $\begin{array}{c}\mathbf{T} \text { forming }\left({ }^{\circ} \mathbf{C}\right) / \\
\mathbf{t}(\mathbf{m i n})\end{array}$ & Deformation & Cooling/medium & $\begin{array}{c}\text { HV10 } \\
(-)\end{array}$ \\
\hline $1240 / 30$ & Water & - & No def. & - & 383 \\
\hline $1240 / 30$ & Water/2 & $1080 / 1.5$ & $5 \times$ & Water & 673 \\
\hline $1240 / 30$ & Water/2 & $1080 / 1.5$ & $10 \times$ & Water & 856 \\
\hline
\end{tabular}

Semi-solid processing with no subsequent mechanical working led to microstructures with a large fraction of austenite. On the other hand, the routes with deformation led to high hardness. After this finding, tempering at two different temperatures was incorporated: $300^{\circ} \mathrm{C}$ for 1 hour, and double tempering at $530^{\circ} \mathrm{C}$, each operation for 1 hour (Table 3 ). The purpose was to determine the stability of austenite after tempering and monitor microstructural evolution in mechanically-worked specimens. Hardness of these materials was measured as well. 
Table 3 Tempering routes for workpieces without and with mechanical working

\begin{tabular}{|c|c|c|c|c|c|}
\hline $\begin{array}{c}\text { T heating }\left({ }^{\circ} \mathrm{C}\right) \\
/ \mathrm{t}(\mathrm{min})\end{array}$ & $\begin{array}{c}\text { Quenching } \\
\text { medium/t (s) }\end{array}$ & $\underset{\mathrm{t}(\min )}{\mathrm{T} \text { forming }}\left[{ }^{\circ} \mathrm{C}\right] /$ & Cooling/medium & $\mathrm{T}$ tempering $\left({ }^{\circ} \mathrm{C}\right) / \mathrm{t}(\mathrm{h})$ & $\begin{array}{c}\text { HV10 } \\
(-)\end{array}$ \\
\hline \multirow{2}{*}{$1240 / 30$} & \multirow{2}{*}{ Water } & \multirow{2}{*}{ - } & \multirow{2}{*}{ No def. } & $300 / 1$ & 378 \\
\hline & & & & $530 / 1$ (2 times) & 530 \\
\hline \multirow{2}{*}{$1240 / 30$} & \multirow{2}{*}{ Water/2 } & \multirow{2}{*}{$1080 / 1.5$} & \multirow{2}{*}{ Water } & $300 / 1$ & 634 \\
\hline & & & & $530 / 1$ (2 times) & 608 \\
\hline \multirow{2}{*}{$1240 / 30$} & \multirow{2}{*}{ Water/2 } & \multirow{2}{*}{$1080 / 1.5$} & \multirow{2}{*}{ Water } & $300 / 1$ & 726 \\
\hline & & & & $530 / 1$ (2 times) & 562 \\
\hline
\end{tabular}

\section{RESULTS AND DISCUSSION}

Semi-solid processing after heating at $1240^{\circ} \mathrm{C}$ for 30 minutes, no subsequent mechanical working and final quenching led to a microstructure of polyhedral austenite grains embedded in ledeburite network. The amount of austenite was around $90 \%$. The network was a mixture of austenite and carbides. Hardness reached 383 HV 10 (Figure 2).

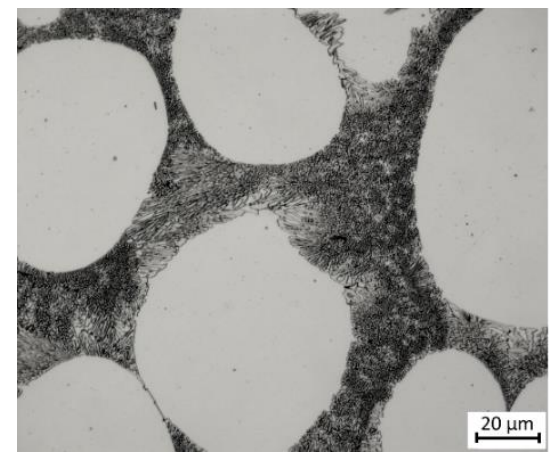

Figure $2-1240^{\circ} \mathrm{C} / 30 \mathrm{~min}$., no mechanical working, light micrograph

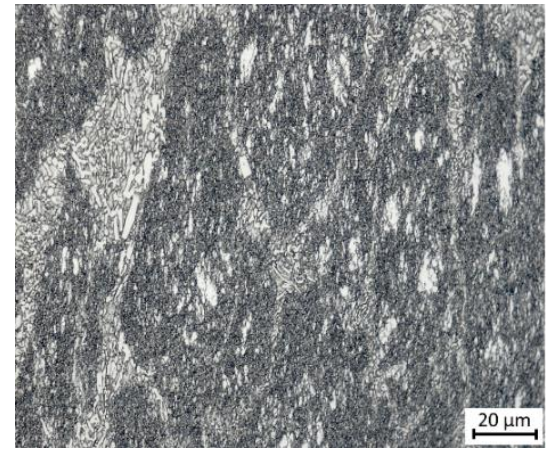

Figure $3-1240^{\circ} \mathrm{C} / 30 \mathrm{~min}$., five deformation steps, light micrograph

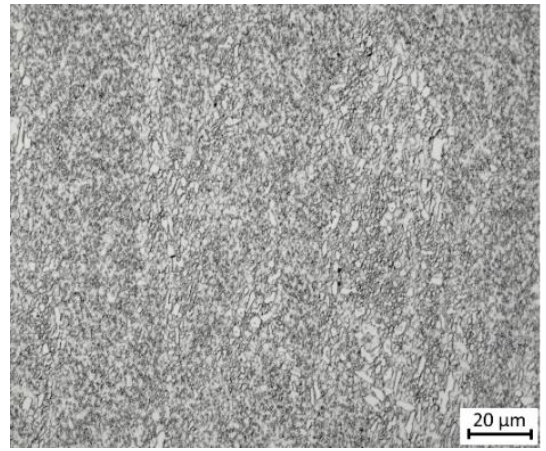

Figure $4-1240^{\circ} \mathrm{C} / 30 \mathrm{~min}$., ten deformation steps, light micrograph

A profound change in the microstructure was found after five deformation steps following cooling to $1080^{\circ} \mathrm{C}$. Mechanical working produced a considerably finer microstructure. The matrix consisted of martensite with a small fraction of untransformed austenite with a dispersion of fine chromium carbides. The amount of austenite was $34 \%$. The microstructure contained small clusters of ledeburite lamellae as a residue of the former network. The secondary carbides were smaller than $1 \mu \mathrm{m}$. Mechanical working led to a higher hardness: 673 HV10 (Figure 3).

Higher number of deformation steps, i.e. ten instead of five, produced an even finer microstructure, broke up the ledeburite even more and led to a more uniform distribution of carbides. The resulting martensitic microstructure was very fine, contained $37 \%$ austenite and a uniform dispersion of chromium carbides. Hardness was very high due to higher number of deformation steps: 856 HV10 (Table 2). No remnants of unbroken ledeburite network were found in the microstructure. There were rare primary chromium carbides which, nevertheless, were much smaller and more globular than those in the as-received material (Figure 4).

Due to the presence of a large amount of austenite after semi-solid processing with no subsequent mechanical working and because of high hardness after routes with mechanical working, additional tempering was applied. The temperatures were $300^{\circ} \mathrm{C}$ and $530^{\circ} \mathrm{C}$. Tempering at $300^{\circ} \mathrm{C}$ led to no substantial changes in the microstructure of specimens after semi-solid processing and no mechanical working. The resulting microstructure consisted of polyhedral austenite grains embedded in a ledeburitic network. Tempering at this temperature had no impact on hardness - which was 389 HV10 (Figures 5, 7). Partial austenite decomposition 
only took place during tempering at $530^{\circ} \mathrm{C}$. The decomposition initiated along its grain boundaries where very fine pearlite formed. Austenite decomposition also occurred in the ledeburitic network. Some martensite needles were found directly within austenite grains. This partial martensite transformation was driven by the reduced carbon content in austenite which in turn was the result of pearlite formation. These microstructural changes were reflected in the increase in hardness from 383 HV10 to 530 HV10 (Figure 5-7).

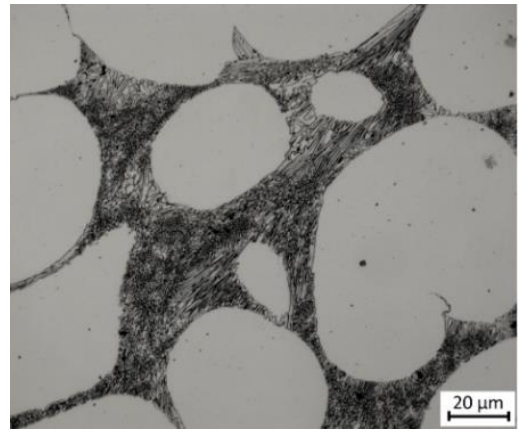

Figure $5-1240{ }^{\circ} \mathrm{C} / 30 \mathrm{~min}$, tempering at $300^{\circ} \mathrm{C}$, light micrograph

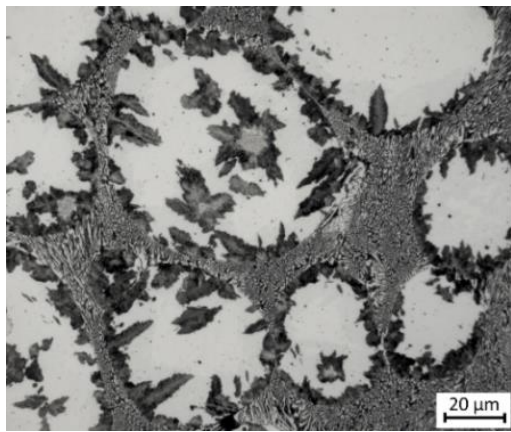

Figure $6-1240{ }^{\circ} \mathrm{C} / 30 \mathrm{~min}$. tempering twice at $530^{\circ} \mathrm{C}$, light micrograph

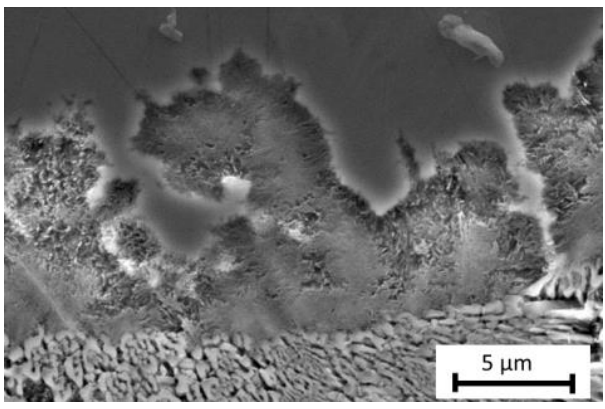

Figure 7 - Detail of pearlite which formed along austenite grain boundaries, scanning electron micrograph

Tempering at the lower temperature of $300^{\circ} \mathrm{C}$ caused no visible changes in the microstructure of specimens with five deformation steps. A very fine microstructure consisting of a martensitic matrix and chromium carbide precipitates was obtained (Figures 8, 9). Tempering of the martensitic matrix reduced hardness from 673 HV10 to $634 \mathrm{HV} 10$ (Figure 9, 11). Tempering at $530^{\circ} \mathrm{C}$ was able to induce greater changes in the microstructure. Tempering at the higher temperature caused the remaining austenite to decompose into very fine pearlite. It also led to a greater degree of tempering of the martensitic matrix. With the higher tempering temperature, hardness decreased from 673 HV10 to 608 HV10 (Figures 10, 12).

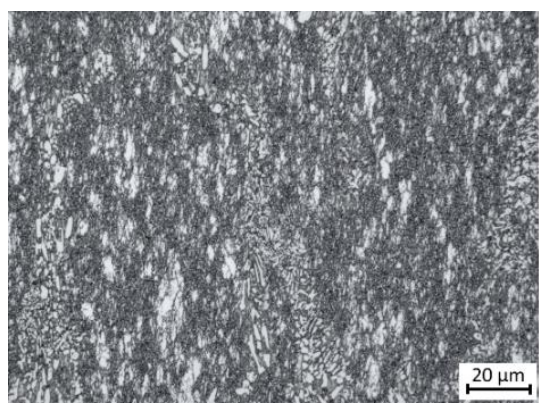

Figure $8-1240{ }^{\circ} \mathrm{C} / 30$ min., 5 deformation steps, tempering at $300^{\circ} \mathrm{C}$, light micrograph

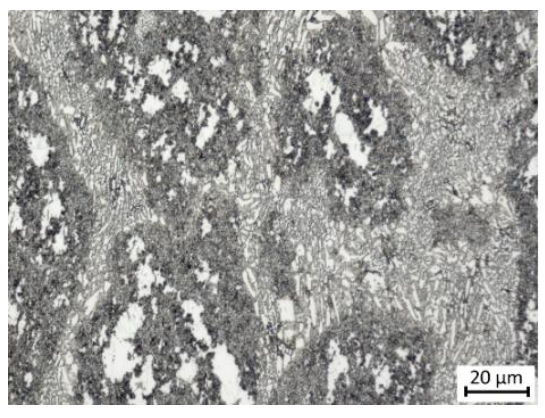

Figure $10-1240^{\circ} \mathrm{C} / 30 \mathrm{~min}$., 5 deformation steps, tempering twice at $530^{\circ} \mathrm{C}$, light micrograph

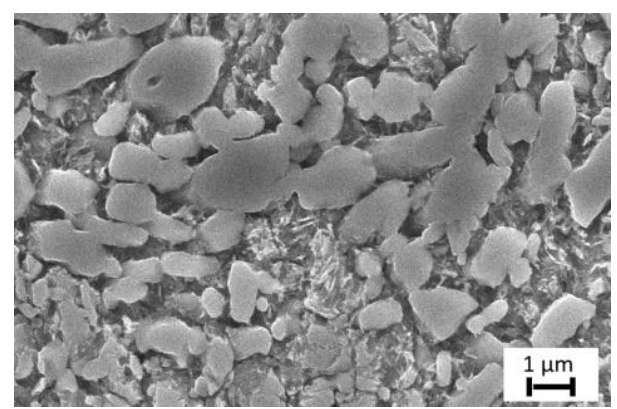

Figure 9 - Detail of microstructure after tempering at $300^{\circ} \mathrm{C}$, light micrograph

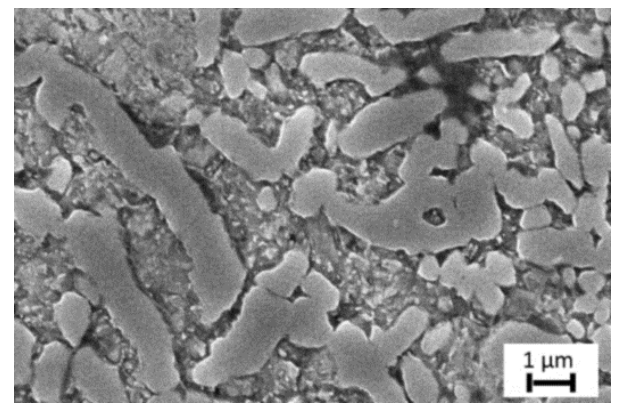

Figure 11 - Detail of microstructure after tempering at $530^{\circ} \mathrm{C}$, optical micrograph 
The route with ten deformation steps led to similar results as the previous one. Tempering at the lower temperature, $300^{\circ} \mathrm{C}$, altered the martensitic matrix and led to a decrease in hardness from $856 \mathrm{HV} 10$ to 726 $\mathrm{HV} 10$. In this microstructure, fine chromium carbides of $\mathrm{M}_{7} \mathrm{C}_{3}$ and $\mathrm{M}_{23} \mathrm{C}_{6}$ types were found. Small areas containing the initial ledeburite network were found as well (Figures 12, 13). The main effect of tempering at the higher temperature, $530^{\circ} \mathrm{C}$, was precipitation of fine chromium carbides in the matrix. The remaining austenite decomposed into pearlite (Figures 14, 15). Hardness decreased even more: to 562 HV10.

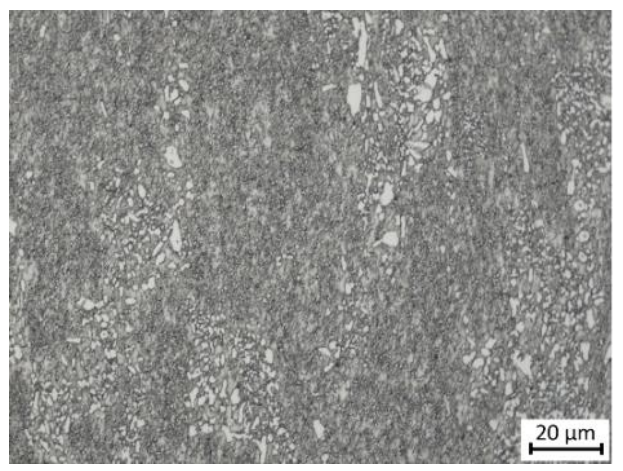

Figure $12-1240^{\circ} \mathrm{C} / 30 \mathrm{~min}$., 10 deformation steps, tempering at $300^{\circ} \mathrm{C}$, light micrograph

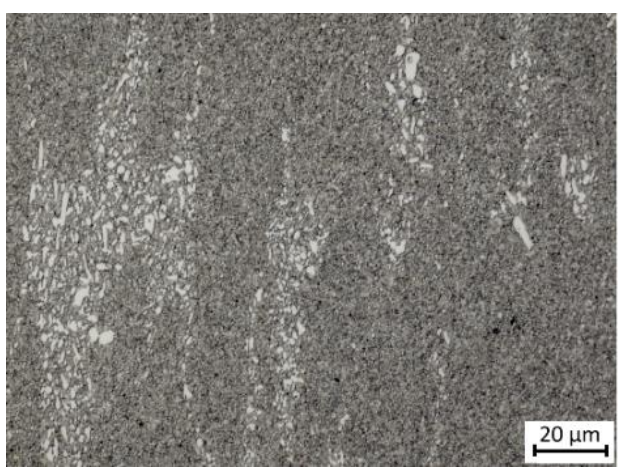

Figure $14-1240^{\circ} \mathrm{C} / 30 \mathrm{~min} ., 10$ deformation steps, tempering twice at $530^{\circ} \mathrm{C}$, light micrograph

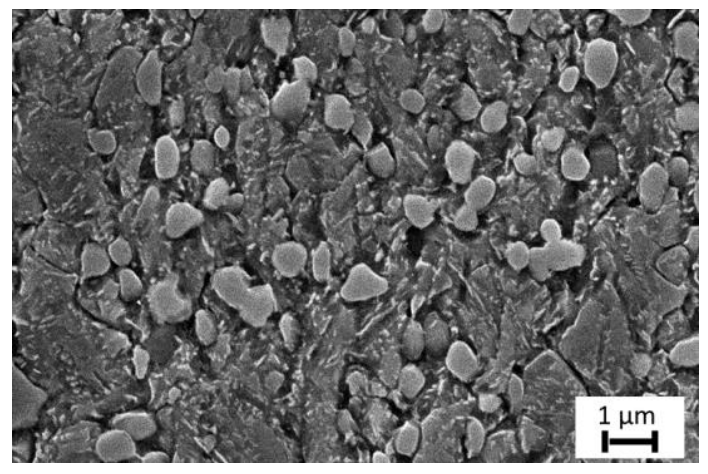

Figure 13 - Detail of microstructure after tempering at $300^{\circ} \mathrm{C}$, optical micrograph

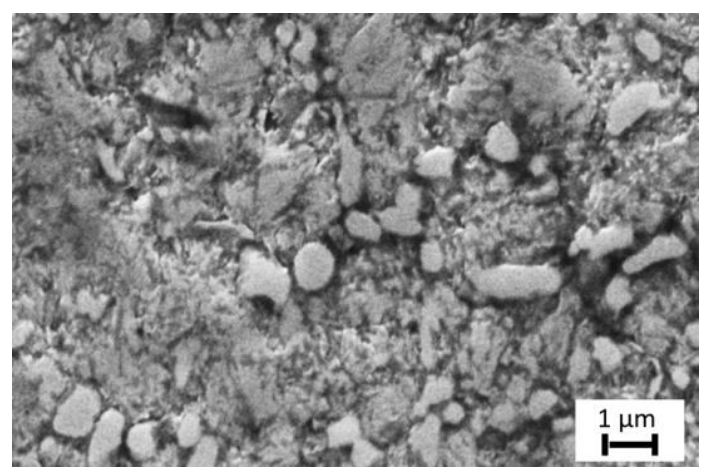

Figure 15 - Detail of microstructure after tempering at $530^{\circ} \mathrm{C}$, optical micrograph

\section{CONCLUSION}

Semi-solid processing with subsequent mechanical working was carried out on X210Cr12 hypereutectoid tool steel. Three conditions of the input feedstock were prepared. The common part of the treatment routes involved heating to the semi-solid region at $1240^{\circ} \mathrm{C}$, holding for 30 minutes and cooling for 1.5 minutes. It was followed by quenching, five deformation steps and ten deformation steps. Then two tempering sequences were applied. The first one was at $300^{\circ} \mathrm{C}$ for 1 hour and the other at $530^{\circ} \mathrm{C}$ for 1 hour which was repeated twice.

The conventional tempering at $300^{\circ} \mathrm{C}$ did not result in any appreciable changes in the microstructure of the material which received no deformation. Changes were seen after double tempering at $530^{\circ} \mathrm{C}$. It led to austenite decomposition and pearlite formation. Hardness increased slightly, to 570 HV10. By contrast, in specimens which received deformation, tempering led to a decrease in hardness. In the materials after five and ten deformation steps, tempering at $300^{\circ} \mathrm{C}$ led to a decrease in hardness by $39 \mathrm{HV} 10$ and $130 \mathrm{HV} 10$, respectively. Even higher decrease was seen after tempering at $530^{\circ} \mathrm{C}: 65 \mathrm{HV} 10$ and $290 \mathrm{HV} 10$ after five and ten deformation steps, respectively. However, that was due to pearlite which formed in the microstructure and which is undesirable. Therefore, this tempering route is unsuitable for further use. 


\section{ACKNOWLEDGEMENTS}

This research was funded by the Technology Agency of the Czech Republic under the project TJ02000182 „Improvement of wear resistance of tool steels by a combination of semi-solid treatment with subsequent hot forming and deep cryogenic treatment".

\section{REFERENCES}

[1] Hoyoung Kim, Jun-Yun Kang, Dongmin Son, Tae-Ho Lee, Kyung-Mox Cho: Evolution of carbides in cold-work tool steels, Materials Characterization, Volume 107, 2015, Pages 376-385.

[2] WANG J, GUO W, SUN H, LI H, GOU H, ZHANG J 2016: Plastic deformation behaviours and hardening mechanism of M7C3 carbide, Materials Science and Engineering A 662 88-94

[3] T. VEČKO PIRTOVŠEK, G. KUGLER, M. TERČLELJ: Materials Characterization, Vol. 83, 2013, p. 97-108, http://dx.doi.org/10.1016/j.matchar.2013.06.008.

[4] ČSN 41 9436. Ocel 19436 chromová, Praha: Český normalizační institut, 1994.

[5] Song Tenbo, Kang Yonglin, Zhao Aimin: Semi-solid rolling process of steel strips, Journal of Materials processing Technology 198 (2008), 291-299

[6] A. RASSILI, H. V. ATKINSON: A review of steel thixoforming. Trans. Nonferrous Met. Soc. China 20(2010) s1048-s1054.

[7] W. PUTTGEN, B. HALLSTEDT, W. BLECK, P.J. Uggowitzer: On the microstructure formation in chromium steels rapidly cooled from the semi-solid state, Acta Materialia 55 (2007) 1033-1042

[8] UHLENHAUT, D.I.; KRADOLFER, J.; PUTTGEN, W.; LOFFLER, J.F.; UGGOWITZER, P.J. Structure and properties of a hypoeutectic chromium steel processed in the semi-solid state. Acta Mater. 2006, 54, 2727-2734.

[9] JIRKOVÁ, H., K. RUBEŠOVÁ, K. OPATOVÁ, M. PEKOVIĆ and B. MAŠEK. Effect of heating temperature during semi-solid processing on structure of X210CR12 steel. Acta Metallurgica Slovaca [online]. 2017, 23(3). ISSN 13381156. Available from: doi:10.12776/ams.v23i3.969.

[10] JIRKOVÁ, H., RUBEŠOVÁ, K., KONOPÍK, P., OPATOVÁ, K. Effect of the Parameters of Semi-Solid Processing on the Elimination of Sharp-Edged Primary Chromium Carbides from Tool Steel. METALS, 2018, roč. 8, č. 9, s. 115. ISSN: 2075-4701. MATTHEWS, J.R., MATTHEWS, W.R. Successful Scientific Writing: A Step-by-Step Guide for the Biological and Medical Sciences. Cambridge: Cambridge University Press, 2008. 